\title{
ADSORPTION PROPERTIES OF NICKEL-BASED MAGNETIC ACTIVATED CARBON PREPARED BY PD-FREE ELECTROLESS PLATING
}

Boyang Jia, Ling Su, Guangqian Han, Guangping Wang, Jian Zhang, and Lijuan Wang *

\begin{abstract}
Nickel-based magnetic activated carbon was synthesized from coconut shell activated carbon by electroless plating with palladium-free activation. The effect of plating solution volume on metallic ratio and adsorption capacity were evaluated. The effect of metallic ratio on specific area, pore volume, and magnetic properties were investigated. The morphologies of activated carbon before and after plating were observed by SEM, and the composition of the layer was analyzed by EDS analysis. The results showed that the metallic ratio was increased with the increase of the plating solution volume. The magnetic activated carbon showed high adsorption capacity for methylene blue and a high iodine number. Those values reached $142.5 \mathrm{mg} / \mathrm{g}$ and $1035 \mathrm{mg} / \mathrm{g}$, respectively. The specific area and pore volume decreased from 943 $\mathrm{m}^{2} / \mathrm{g}$ to $859 \mathrm{~m}^{2} / \mathrm{g}$ and $0.462 \mathrm{ml} / \mathrm{g}$ to $0.417 \mathrm{ml} / \mathrm{g}$, respectively. And the layer was more compact and continuous when the metallic ratio reached $16.37 \mathrm{wt} . \%$. In the layer, there was about $97 \mathrm{wt} . \%$ nickel and $3 \mathrm{wt} . \%$ phosphorus, which indicates that the layer was a low-phosphorus one. At the same time, magnetism was enhanced, making the product suitable for some special applications.
\end{abstract}

Keywords: Activated carbon; Electroless nickel plating; Palladium-free; Magnetic; Adsorption Capacity

Contact information: Key Laboratory of Bio-based Material Science and Technology of Minister of Education, Northeast Forestry University, 26 Hexing Road, Harbin 150040, P. R. China; *Corresponding author:donglinwlj@163.com

\section{INTRODUCTION}

In recent years, increasing concern for public health and environmental quality has led to growing interest in developing and implementing various methods of removing potentially toxic organic and inorganic pollutants from water (Chowdhury et al. 2004). Activated carbon is often used as an adsorbent for the removal of various organic compounds because of its high surface area, porous structure, and special surface reactivity (Gadkaree 1998). This sorbent is highly inert and thermally stable, and it can be used over a broad pH range. Furthermore, powdered activated carbon can quickly adsorb organic and inorganic contaminants from water. When the activated carbon becomes exhausted or the effluent reaches the maximum allowable discharge level, the carbon needs to be separated from the aquatic system and regenerated. Unfortunately, fine activated carbons are extremely difficult to separate from solution, because the traditional method for separating powdered activated carbon is filtration, and it could cause the blockage of filters or the loss of carbon (Clifford et al. 1983). Thus, the difficulties 
encountered in separating and regenerating spent activated carbon limits its applications in many fields.

Recently, attempts to use magnetic separation by applying an appropriate magnet have been reported for nanoparticles iron oxide or cobalt incorporated in mesoporous silica, such as MCM-41, MCM-48, and SBA-15 (Lu et al. 2004a,b). Magnetic separation, which represents a group of techniques based on the use of magnetic or magnetizable adsorbents, carriers, and cells, has been used for many applications in biochemistry, microbiology, cell biology, analytical chemistry, mining ores, and environmental technologies (Safarik et al. 1995; Velsen and Vos 1991; Setchell 1985). Examples of this technology are the use of magnetic particles to accelerate the coagulation of sewage (Booker et al. 1991), a magnetic-coated functionalized polymer such as a resin to remove radionuclides from milk (Sing 1994), poly(oxy-2,6-dimethyl-1,4-phenylene) for the adsorption of organic dyes (Safarik et al. 1995), and polymer-coated magnetic particles for oil spill remediation (Orbell et al. 1997). However, most of these materials have the drawbacks of small adsorption capacity and narrow application range.

To overcome the disadvantages of powdered activated carbon and magnetic particles, several methods such as impregnation (Wang et al. 1994), ball milling (Rudge et al. 2000), and chemical coprecipitation (Safarik et al. 1997; Oliveira et al. 2002) have been developed to combine them together to produce magnetic composites, which could be used as adsorbents to remove a wide range of organic pollutants over a broad $\mathrm{pH}$ range and be conveniently separated by magnetic separation technology. But the preparations of those materials were often complicated; thus these kinds of materials have not been shown to be appropriate for industry.

Herein, we use the method of Pd-free electroless plating, which is reported in the literature (Jia and Wang 2010) to synthesize the nickel-based magnetic activated carbon. It can reduce the cost of the catalyst, simplify the process of coating the adhesionpromoting layer on the chitosan film, and can be adapted for large-scale commercial manufacturing. In the past work, we have studied on the microwave absorbing properties of the Ni-based activated carbon. In the present work, we explore the adsorption properties of Ni-based activated carbon. The surface areas and total pore volumes are determined. And the adsorbents generated were subjected to adsorption tests in the liquid phase using both methylene blue and iodine as adsorbates to be retained. In this way, adsorption capacities of the two adsorbates were analyzed. The powder is expected to possess advantages common to both activated carbon and metal powder. The magnetic properties of the powder were studied.

\section{EXPERIMENTAL}

\section{Materials}

The Hainan Xingguang Activated carbon Company of China supplied the activated carbon. Chitosan (CTS, Deacetyl Degree 92\%) was purchased as industrial grade power from Jinan Haidebei Chemical Agent Ltd. All other chemicals used were of analytical grade purity. 


\section{Preparation of Ni-based Activated Carbon}

The nickel-based activated carbon was synthesized by electroless plating with palladium-free activation. The method was mentioned in the literature (Jia and Wang 2010). In this process, chitosan was loaded onto the activated carbon surface, which performed as a CTS film around the activated carbon particles (AC-CTS for short). Then the AC-CTS were immersed in plating solution. In this way, more $\mathrm{Ni}^{2+}$ was adsorbed on the AC-CTS particles during the activating process. Afterwards $\mathrm{NaBH}_{4}$ served as a reducing agent to reduce $\mathrm{Ni}^{2+}$ into $\mathrm{Ni}^{0}$. When the AC-CTS-Ni was placed into the plating solution, $\mathrm{Ni}^{\circ}$ was immediately nucleated and served to catalyze the subsequent electroless deposition.

The original plating solution used is shown in Table 1.

Table 1. Composition of Original Nickel-Plating Solution

\begin{tabular}{|c|c|}
\hline Chemicals & $\begin{array}{c}\text { Content } \\
\left(\mathrm{g} \cdot \mathrm{L}^{-1}\right)\end{array}$ \\
\hline $\mathrm{NiSO}_{4} \cdot 6 \mathrm{H}_{2} \mathrm{O}$ & 30 \\
\hline $\mathrm{NaH}_{2} \mathrm{PO}_{2} \cdot \mathrm{H}_{2} \mathrm{O}$ & 30 \\
\hline Lactate and NaAc & 35 \\
\hline $\mathrm{NH}_{4} \mathrm{Cl}$ & 25 \\
\hline $\mathrm{Thiourea}$ & 0.002 \\
\hline $\mathrm{pH}$ & $8-9$ \\
\hline
\end{tabular}

\section{Characterization Methods}

The composition of deposits was determined by X-ray energy dispersion spectroscopy (EDS) equipped on the Quanta 200 electron microscope. The morphology was observed using scanning electron microscopy (SEM) before and after plating.

\section{Measurement of Metal Ratio}

The commonly used technique involving gravimetric analysis was not effective for determining the amount of deposited metal, because the nickel-based activated carbon powder was lost slightly during the course of the whole experimental process. So we used concentrated nitric acid to dissolve the deposited metal, and the concentration of nickel deposited $\left(\mathrm{C}_{1}\right)$ was determined by atomic absorption spectrometry. The metallic ratio was calculated as follows,

$$
\text { Metallic ratio }(\%)=\frac{C_{1} \times M_{N i}}{m_{0}} \times 100 \%
$$

where $M_{N i}$ is the mole mass of nickel, and $m_{0}$ is the mass of plated activated carbon.

\section{Measurement of Pore Volume and Specific Area}

Adsorption-desorption isotherms of nitrogen at $196{ }^{\circ} \mathrm{C}$ below zero were measured with an automatic adsorption instrument (Nova-1000 Gas Sorption analyzer, U.S.A.) in order to determine surface areas and total pore volumes. Prior to the measurements, the samples were out-gassed at $300{ }^{\circ} \mathrm{C}$ under nitrogen for at least $3 \mathrm{~h}$. The total pore volumes were estimated to be the liquid volumes of adsorbate $\left(\mathrm{N}_{2}\right)$ at a relative pressure of 0.99 . 
The surface area of the samples was calculated by the Brunauer-Emmet-Teller (BET) method in relative pressure $\left(P / P_{0}\right)$ range of 0.05 to 0.30 at $196{ }^{\circ} \mathrm{C}$ below zero.

\section{Characterization by lodine Number}

The standard test method for the determination of iodine number of activated carbon was used (ASTMD4607-94, 1995), whereby values must have a coefficient of determination $\left(\mathrm{R}^{2}\right)$ of over 0.995 (Rozada et al. 2003).

\section{Liquid Phase Adsorption of Methylene Blue}

By batch experimentation, methylene blue (MB) solution was mixed with activated carbon and shaken $(200 \mathrm{rpm})$ at room temperature. After the reaction, the solutions were filtered, and the concentrations of methylene blue solution were then determined by an Agilent $8453 \mathrm{UV}$-Vis spectrophotometer (Germany) at $663 \mathrm{~nm}$. The equilibrium adsorption capacities $\left(q_{e}\right)$ of the activated carbon were determined based on adsorbate mass balance using equation (2),

$$
q_{e}=\frac{\left(C_{o}-C_{e}\right) v}{M}
$$

where $c_{0}$ and $c_{e}$ are the initial and equilibrium concentrations of the MB solution(mg/L), respectively, $v$ is the volume of the aqueous solution (L), and $M$ is the mass of plated activated carbon used (g) (Kumar et al. 2005).

\section{Measurement of Magnetic Properties}

Magnetic properties were measured using a vibrating sample magnetometer (VSM) (Lake Shore 7407). The complex permittivity and permeability of the activated carbon/paraffin wax composites were measured by the coaxial line method at 2 to18 $\mathrm{GHz}$, using an HP8722ES network analyzer in agreement with the method reported in (Liu and Zhao 2005). The content of the activated carbon was $10 \mathrm{wt}$. \%.

\section{RESULTS AND DISCUSSION}

\section{The Effects of Plating Volume on Metallic Ratio}

Figure 1 shows the effect of the plating solution volume on metallic ratios of the nickel-based activated carbon in plating solutions having different concentrations at a fixed plating time of 1 minute. As shown in Fig. 1, the metallic ratios of the plated activated carbon were increased with the increase of the volumes of plating solution. And the overall metallic ratio of nickel-based activated carbon prepared by using 2 times dilution of the original plating solution was higher than that prepared with 4 times dilution. Thus, it was possible to change the metallic ratio of the nickel-based activated carbon by changing the plating solution volume and concentration in the experiment. 


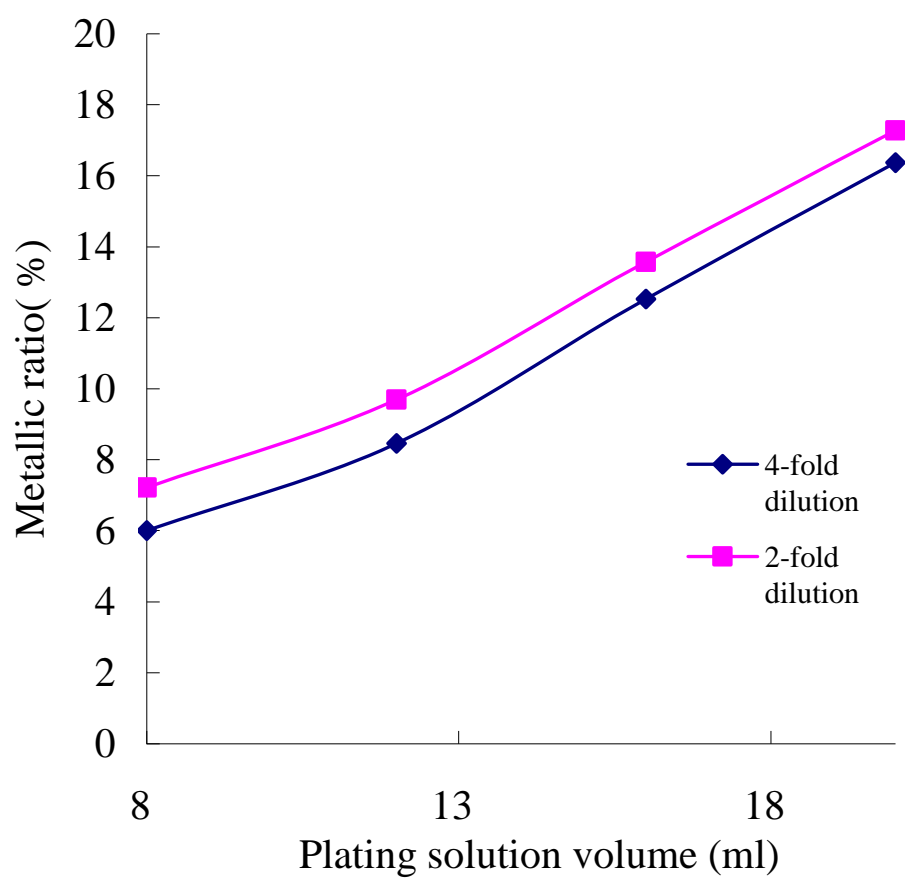

Fig. 1. Effect of plating solution volume on metallic ratio of nickel-based activated carbon

\section{Effects of Metallic Ratio on Surface Area and Pore Volume}

Table 2 shows the results from surface area measurements for different metallic ratios of the samples. As can be seen, higher metallic ratios can lead to smaller surface area. In addition, the pore diameter distributions of the nickel-based activated carbon were decreased with the increase of the metallic ratio of the samples. This may be because some nickel-phosphor alloy entered into and deposited onto the inner wall of the pores of activated carbon.

Table 2. Surface Area Measurement of the Different Samples

\begin{tabular}{ccc}
\hline Metallic ratio $(\%)$ & BET specific surface $\left(\mathrm{m}^{2} / \mathrm{g}\right)$ & Pore volume $(\mathrm{mL} / \mathrm{g})$ \\
\hline 0 & 942.86 & 0.462 \\
3.35 & 879.00 & 0.424 \\
16.37 & 859.12 & 0.417 \\
\hline
\end{tabular}

\section{Surface Morphology and Phase Structure of the Coating}

The morphologies of the uncoated activated carbon and nickel-based activated carbon with two metallic ratios are shown in Fig. 2. The SEM photographs of uncoated activated carbon particles in Fig. 2(a) showed that the surface had many pores in a generally smooth surface. SEM micrographs of the nickel-based activated carbon with the metallic ratio of $3.35 \%$ and $16.37 \%$ are presented in Figs. 2(b) and (c), respectively. In Fig. 2(b), small aggregates are observed, which appear brighter, supported on the darker surface of the activated carbon. The coating was clearly loose and non-uniform. And the porous structure can be seen clearly. Compared with Fig. 2(b), the surface of nickel-based activated carbon with the metallic ratio of $16.37 \%$ was covered by a coating, which was uniform, compact, and continuous. It can be also observed that the coating 
was composed of small cells. These cells were deposited together closely. The porous structure was still present. But some of the pores were blocked, which provides further evidence that the pore diameter decreased.
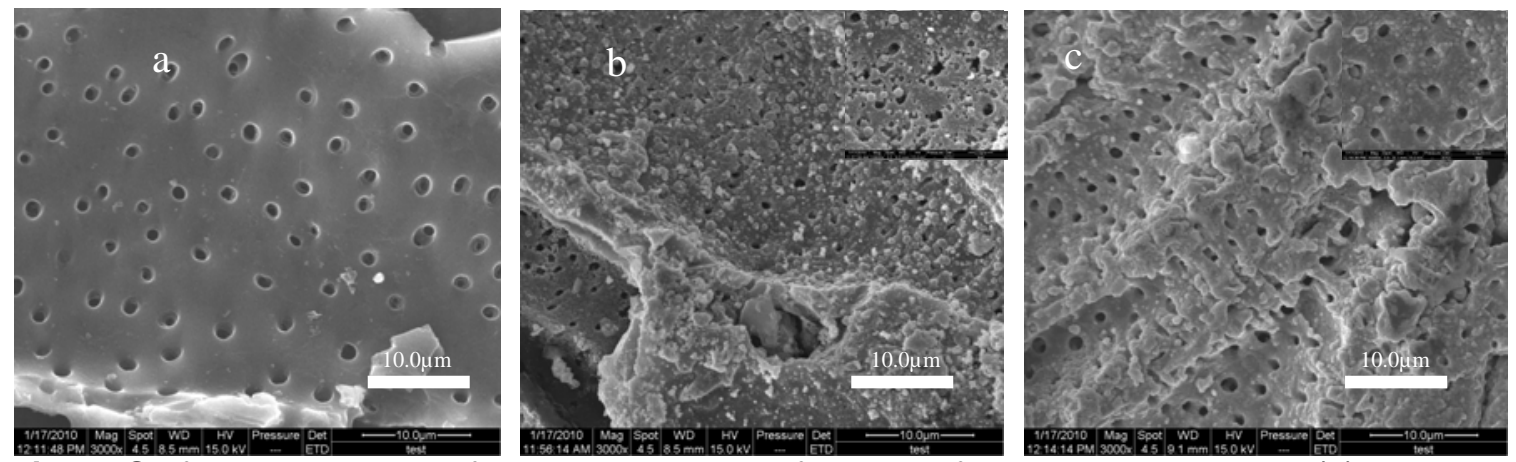

Fig. 2. Surface morphology of activated carbon before and after electroless plating: (a) uncoated activated carbon; (b) Nickel-based activated carbon with metallic ratio of 3.35\%; (c) Nickel-based activated carbon with metallic ratio of $16.37 \%$

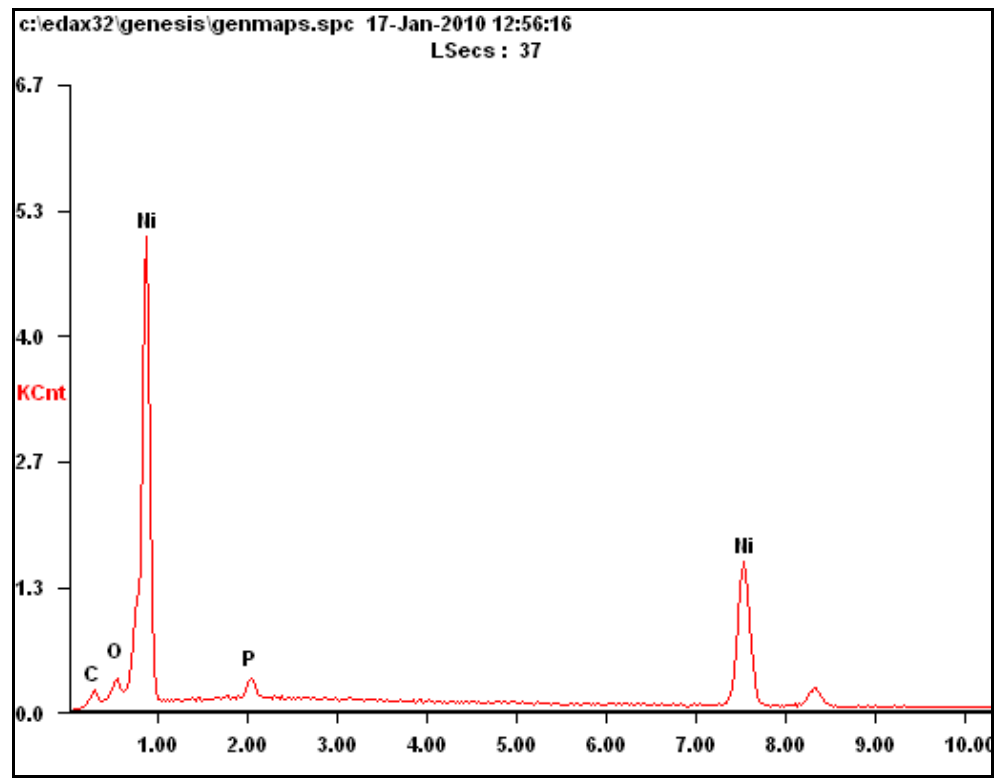

Fig. 3. EDS spectrum of plated activated carbon

Figure 3 shows the EDS spectrum of the plated activated carbon. Peaks of carbon and oxygen are from activated carbon, and nickel and phosphorus were attributed to the coating. At the beginning of the process, $\mathrm{Ni}^{2+}$ on activated carbon-CTS reacts with $\mathrm{NaBH}_{4}$ to produce catalytic $\mathrm{Ni}^{0}$; $\mathrm{Ni}^{\mathrm{O}}$ cluster immediately catalyzed the subsequent electroless $\mathrm{Ni}-\mathrm{P}$ codeposition. It is proved by the EDS results that the film consisted of a $\mathrm{Ni}-\mathrm{P}$ alloy. However, the element boron was not checked. The results indicated that a reaction took place when specimens with $\mathrm{Ni}^{2+}$ were placed in the plating $\mathrm{NaBH}_{4}$ solution. The reaction can be written as:

$$
2 \mathrm{Ni}^{2+}+\mathrm{BH}_{4}^{-}+2 \mathrm{H}_{2} \mathrm{O} \rightarrow 2 \mathrm{Ni}^{\mathrm{o}}+2 \mathrm{H}_{2} \uparrow+\mathrm{BO}_{2}{ }^{-}+4 \mathrm{H}^{+}
$$


Therefore, there was no boron depositing together with $\mathrm{Ni}^{\circ}$ in the activation stage.

Table 3 shows the composition of the layers on activated carbon prepared at two metallic ratios. Although the metallic ratios were quite different, the compositions of the coatings were close to each other. The composition of the coating was mainly affected by the $\mathrm{pH}$ value of the plating solution. The $\mathrm{pH}$ value changed very little in the diluting process because there was a buffer. Therefore, the contents of $\mathrm{Ni}$ or $\mathrm{P}$ changed relatively little.

Table 3. The Composition of the Layers on Activated Carbon

\begin{tabular}{|c|c|c|}
\hline Metallic ratio (\%) & Ni content (\%) & P content (\%) \\
\hline 3.35 & 97.09 & 2.91 \\
\hline 16.37 & 97.27 & 2.73 \\
\hline
\end{tabular}

\section{Methylene Blue Number and lodine Number}

The effect of the plating solution volume on the methylene blue number of the adsorbent (Fig. 4) shows that the quantity of methylene blue adsorbed began to decrease with an increase of plating solution volume. The amount of methylene blue adsorption of nickel-based activated carbon was less than that of untreated activated carbon. And the higher concentrations of the plating solution made the adsorption of methylene blue on activated carbon decrease more. Methylene blue is the most recognized probe molecule for assessing the ability of the sorbent to remove large molecules via its macroporosity (pore diameter greater than $1.5 \mathrm{~nm}$ ). Thus, the result indicated that the macropore numbers of the plated activated carbon were reduced with the increasing of metallic ratio.

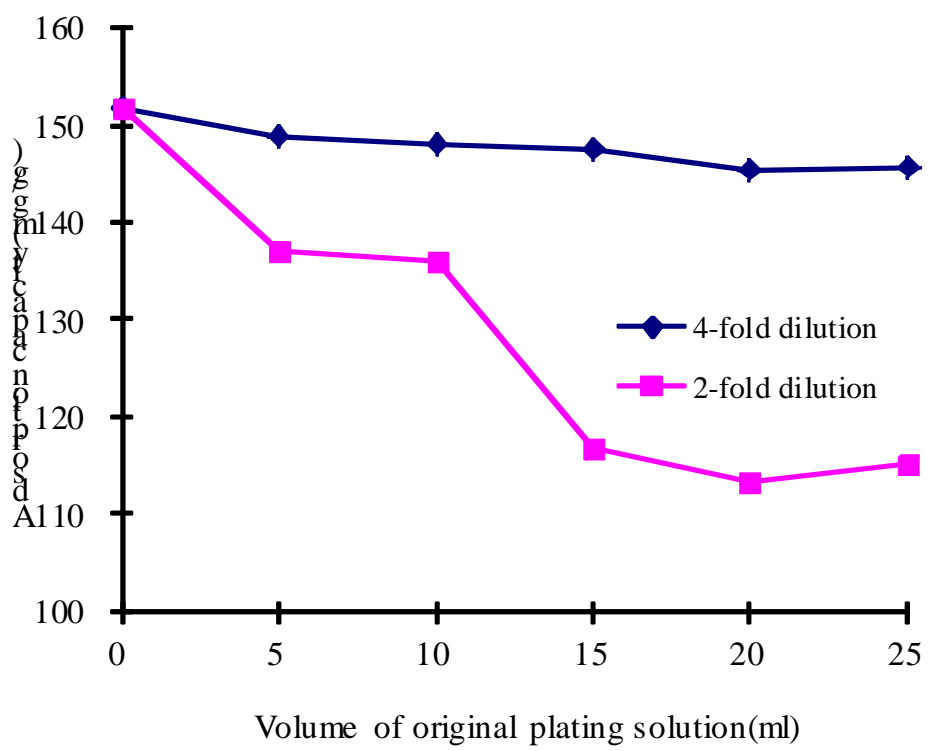

Fig. 4. Effect of plating solution volume on methylene blue numbers of nickel-based activated carbon 
In contrast to methylene blue, the iodine number gives an indication on microporosity (pores less than $1 \mathrm{~nm}$ in diameter). The effect of the plating solution volume and concentration on the iodine number are illustrated in Fig. 5. The nickel-based activated carbon showed a higher iodine number than untreated activated carbon. With the increasing of the plating solution volume, the iodine number first increased slightly, and then it decreased when the volume of the plating solution was more than $20 \mathrm{~mL}$. As is well known, if the macropores of the activated carbon were blocked, some of them changed into micropores. The iodine numbers of the nickel-based activated carbon in low plating solution concentration were higher than that in high solution concentration. Low concentration solution can result in the deposition of a more uniform coating onto the inner walls of pores. However, a high concentration of solution will tend to deposit nonuniform coatings onto the inner wall of pores, which resulted in the blockage of some pores and a decrease in the diameter of some other pores. Thus, any contributions to increased iodine number attributable to uniform deposition were partly counteracted by the decreases associated with blocked pores. When original plating solution reached 20 $\mathrm{mL}$, the total amount of main salt and reducing agent were so high that the deposition filled up more and more pores. Therefore, the iodine number decreased significantly.

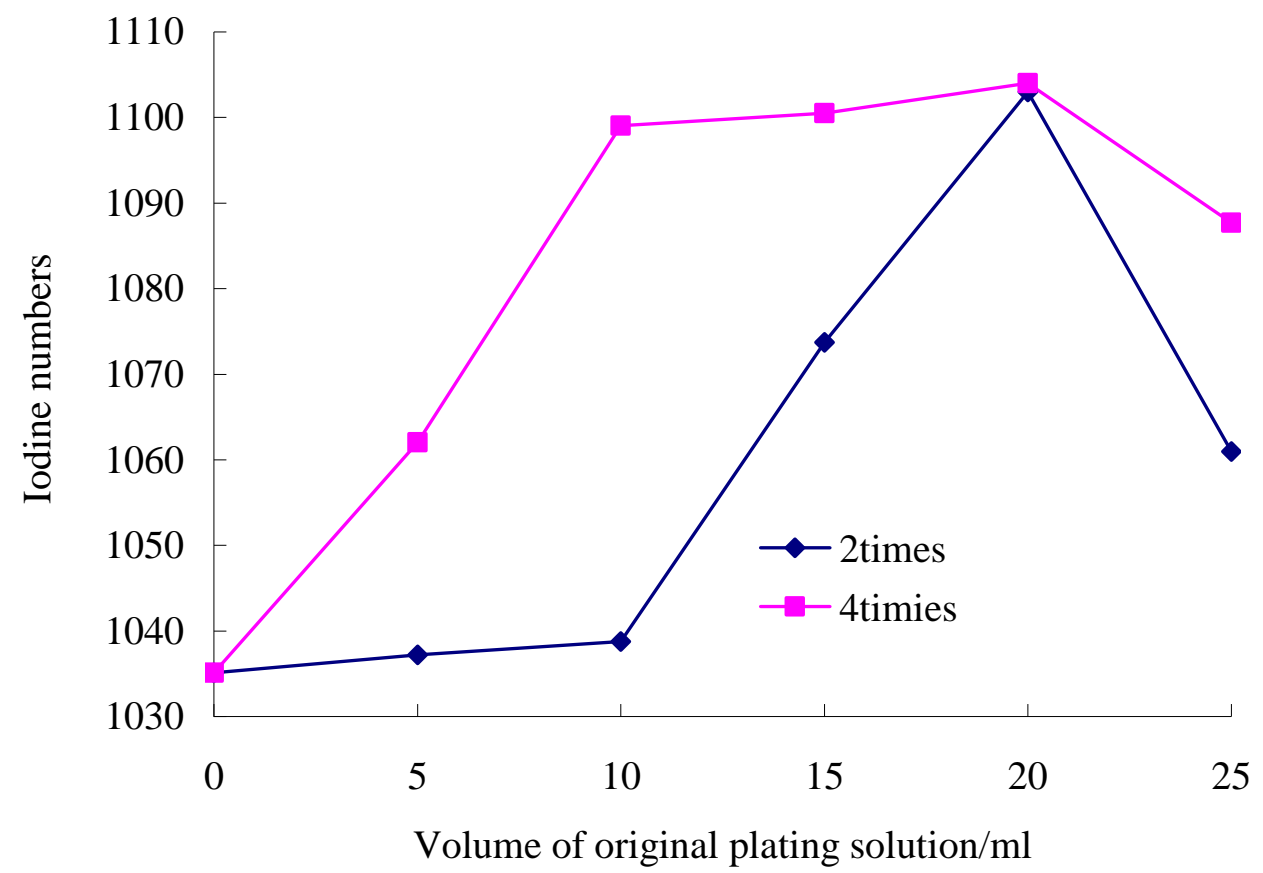

Fig. 5. Effect of plating solution volume on iodine numbers of nickel-based activated carbon

\section{VSM Analysis}

The magnetic properties of nickel-based activated carbon with different metallic ratios were measured by VSM. From VSM experiments, the magnetic parameters such as coercivity $(H c)$, saturation magnetization $(M s)$, and remnant magnetization $(M r)$ were obtained, and results are given in Table 4. With the increase of the metallic ratio, both the saturation magnetization and remnant magnetization were increased. It can be seen that 
the deposit was suitable as a soft magnetic material, because it possessed a high saturation magnetization and low coercivity, and the samples were superparamagnetic, as confirmed from the low $H c$ values. It follows that they can be separated easily in a suspended system. Moreover, the particles can be re-dispersed after they are separated by an external magnetic field because of their low $M r$ values.

Table 4. Magnetic Parameters of the Nickel-Based Activated Carbon with Different Metallic Ratio

\begin{tabular}{cccc}
\hline Metallic ratio $(\%)$ & $M s(\mathrm{emu} / \mathrm{g})$ & $M r(\mathrm{emu} / \mathrm{g}) \times 10^{-3}$ & $H c(\mathrm{G})$ \\
\hline 3.35 & 0.12 & 0.01582 & 33.33 \\
6 & 0.25 & 0.02845 & 20.31 \\
8.46 & 0.33 & 0.05009 & 22.51 \\
12.53 & 0.57 & 0.07614 & 26.17 \\
\hline
\end{tabular}

\section{CONCLUSIONS}

1. Ni-based activated carbon was successfully prepared by electroless plating with palladium-free activation. It was confirmed that the formed $\mathrm{Ni}$ was effective as a catalyst for nickel electroless plating.

2. SEM and EDS analyses showed that the surface of the Ni-based activated carbon was entirely covered with a layer of uniform and continuous Ni-P alloy, which made the activated carbon more like metal, while the pore structure of Ni-based activated carbon could be still seen clearly. The composition of the Ni-P layer was about $97 \%$ of $\mathrm{Ni}$ and $3 \%$ of $\mathrm{P}$. The coating was classed as low-phosphorus deposition.

3. A slight decrease in the surface area and in the microporosity of the activated carbon was caused by the presence of nickel deposition. The composites showed slightly lower adsorption capacity for methylene blue and slightly higher adsorption capacity for iodine number because some nickel-phosphor alloy entered into and deposited onto the inner wall of the pores of activated carbon, and the pore diameter distributions of the nickel-based activated carbon were decreased with the increase of the metallic ratio of the samples.

4. The value of the saturation magnetization, the remnant magnetization, and the coercivity indicated that the nickel-based activated carbon could be classified as a soft magnetic material, and the samples were superparamagnetic, as confirmed from the low Hc values. This means that they can be separated easily in a suspended system. Moreover, the particles can be re-dispersed after they are separated by an external magnetic filed because of their low $M r$ values.

\section{ACKNOWLEDGMENTS}

The authors gratefully acknowledge the Program for NCET (08-0752) and National innovation experiment program for university students in NEFU (091022510). 


\section{REFERENCES CITED}

Booker, N. A., Keir, D., Priestley, A., Rithchie, C. B., Sudarmana, D. L., and Woods, M. A. (1991). "Sewage clarification with magnetite particles," Water Sci. Technol. 23(79), 1703-1712.

Chowdhury, S. R., Jesmeen, A. N., and Hossain, M. M. (2004). "Removal of dyes from water by conducting polymeric adsorbent,” Polym. Adv. Technol. 15, 633-638.

Clifford, D., Chu, P., and Lau, A. (1983). "Thermal regeneration of powdered activated carbon (PAC) and PAC-biological sludge mixtures,” Water Res. 17, 1125-1138.

Gadkaree, K. P. (1998). “Carbon honeycomb structures for adsorption applications," Carbon 36, 981-989.

Jia, B. Y., and Wang, L. J. (2010). "Preparation of microwave absorbing nickel-based activated carbon by electroless plating with palladium-free activation,” BioResources 5(4), 2248-2257.

Kumar, B. G. P., Miranda, L. R., and Velan, M. (2005). “Adsorption of Bismark Brown dye on activated carbon sprepared from rubberwood sawdust (Hevea brasiliensis) using different activation methods,” J. Hazard. Mater. B126, 63-70.

Liu, X. L., and Zhao, D. L. (2006). "Microwave permittivity of multi-walled carbon nanotubes,” Adv. Mater. Res. 11-12, 559-562.

Lu, A. H., Li, W. C., Kiefer, A., Schmidt, W., Bill, E., Fink, G., and Angew, F. S. (2004a). "Fabrication of magnetically separable mesostructured silica with open pore system,” J. Am. Chem. Soc. 126, 8616-8617.

Lu, A.-H., Schmidt, W., Matoussevitch, N., Bönnemann, H., Spliethoff, B., Tesche, B., Bill, E., Kiefer, W., and Schüth, F. (2004b). "Nanoengineering of a magnetically separable hydrogenation catalyst,” Chem. Int. Ed. Engl. 43(33), 4303-4306.

Oliveira, L. C. A., Rios, R. V. R. A., Fabris, J. D., Garg, V., Sapag, K., and Lago, R. M. (2002). "Activated carbon/iron oxide magnetic composites for the adsorption of contaminants in water," Carbon 40, 2177-2183.

Orbell, J. D., Godhino, L., Bigger, S. W., Nguyen, T. M., and Ngeh, L. N. (1997). “Oil spill remediation using magnetic particles,” J. Chem. Educ. 74, 1446.

Rozada, F., Calvo, L. F., García, A. I., Martin-Villacorta, J., and Otero, M. (2003). “Dye adsorption by sewage sludge-based activated carbons in batch and fixed-bed systems,” Bioresour. Technol. 87, 221-230.

Rudge, S. R., Kurtz, T. L., Vessely, C. R., Catterall, L. G., and Williamson, D. L. (2000). "Preparation, characterization, and performance of magnetic iron-carbon composite microparticles for chemotherapy,” Biomaterials 21, 1411-1420.

Safarik, I., Nymburska, K., and Safarikova, M. (1997). "Adsorption of water soluble organic dyes on magnetic charcoal,” J. Chem. Tech. Biotechnol. 69, 1-4.

Safarik, I., Safarikova, M., and Buricova, V. (1995). "Sorption of water soluble organic dyes on magnetic poly(oxy-2,6-dimethyl-1,4- phenylene," Collect Czech. Chem. Commun. 60, 1448-1456.

Safarik, I., Safaríková, M., and Forsythe, S. J. (1995). "The application of magnetic separations in applied microbiology,” J. Appl. Bacteriol. 78, 575-585. 


\section{bioresources.com}

Setchell, C. H. (1985). "Magnetic separations in biotechnology - A review,” J. Chem. Tech. Biotechnol. 35, 175-182.

Sing, K. S. (1994), “Technology profile.” Ground Water Monitor 1994, 60-76.

Velsen, A. F. M., and Vos, G. (1991). "High gradient magnetic separation technique for wastewater treatment,” Water Sci. Technol. 24, 195-203.

Wang, C. L., Liu, Q. C., and Cheng, X. Z. (1994). “Adsorption and desorption of gold on the magnetic activated carbon,” J. Mater. Sci. Technol. 10, 151-153.

Article submitted: September 28, 2010; Peer review completed: October 30, 2010; Revised version received: November 6, 2010; Accepted: November 15, 2010; Published: November 18, 2010. 